\section{Case Reports in Ophthalmology}

\title{
Recurrent Uveal Effusion after Laser Iridotomy
}

\author{
Hiroshi Sakai Michiko Yonahara Miyako Sakai \\ Ophthalmology, University of the Ryukyus, Nishihara, Japan
}

\section{Keywords}

Uveal effusion · Laser iridotomy · Acute primary angle closure

\begin{abstract}
A 59-year-old woman was seen by an ophthalmologist for blurred vision, ocular pain, headache, and nausea. She was diagnosed with acute primary angle closure (APAC) and successfully treated with medications. Using ultrasound biomicroscopy (UBM), engorged episcleral vein was observed and small uveal effusion was diagnosed after laser peripheral iridotomy (LPI). The uveal effusion disappeared and was again diagnosed by UBM together with anterior segment inflammation with ocular pain. Iritis caused by LPI after APAC might be a cause of uveal effusion in this specific case.

(C) 2017 The Author(s)

Published by S. Karger AG, Basel
\end{abstract}

\section{Introduction}

Laser iridotomy can relieve a relative pupillary block and open the angles in primary angle closure disease (PACD) patients [1]. Although laser iridotomy had been accepted as a first-choice therapy for PACD, several postoperative complications have been reported such as iritis, corneal edema, transient elevation of intraocular pressure (IOP), or closure of iridotomy hole [2]. Choroidal detachment and retinal detachment [3] following argon laser peripheral iridotomy (LPI) in a patient with acute primary angle closure (APAC) has been reported. Using ultrasound biomicroscopy (UBM), uveal effusion in PACD eyes with or with- 


\section{Case Reports in Ophthalmology}

Case Rep Ophthalmol 2017;8:26-30

DOI: 10.1159/000455038

(c) 2017 The Author(s). Published by S. Karger AG, Basel www.karger.com/cop

Sakai et al.: Recurrent Uveal Effusion after Laser Iridotomy

out LPI has been reported [4-7]. To study the relation between uveal effusion and laser iridotomy, we observed a temporal course of uveal effusion using UBM in a patient with APAC.

\section{Case Report}

A 59-year-old woman was seen by an ophthalmologist for blurred vision, ocular pain, headache, and nausea. She had no notable medical history. On initial examination, her IOP was $70 \mathrm{~mm} \mathrm{Hg}$ in the right eye (RE) and $14 \mathrm{~mm} \mathrm{Hg}$ in the left eye (LE) by non-contact tonometry. Slit-lamp examination showed dilated pupil and corneal edema in her right eye, and bilateral shallow anterior chamber. She was diagnosed with APAC. Then oral acetazolamide $500 \mathrm{mg}$ and $2 \%$ pilocarpine eye drop every $1 \mathrm{~h}$ were given, and she was referred to the glaucoma clinic at Ryukyu University Hospital immediately. On the same day, IOP was RE, 56 and LE, $12 \mathrm{~mm} \mathrm{Hg}$ by Goldmann tonometry in our clinic. Intravenous injection of $300 \mathrm{~mL}$ mannitol was performed and topical $0.5 \%$ timolol twice daily was started and $2 \%$ pilocarpine eye drop was continued every $15 \mathrm{~min}$. During these medical treatments, UBM (model UX-02, Rion, Tokyo) examination was performed. UBM examination showed closed angle with engorged episcleral veins. Supraciliary space was not observed by UBM at this time (Fig. 1a, b). On the next day, IOP of the right eye came down to $9 \mathrm{~mm} \mathrm{Hg}$ by medical treatment. Slit-lamp examination showed Descemet's membrane fold and (+++) cells in the anterior chamber of the right eye. UBM examination was repeated and revealed narrow but open angle circumferentially and engorged episcleral veins. Uveal effusion was again not evident (Fig. 1c, d). Topical 2\% pilocarpine 4 times daily was applied for both eyes. Axial lengths measured by A-mode ultrasound instrument (Bio and Pachy Meter AL-1000, Tomey, Tokyo) were RE, 23.06 and LE, $23.24 \mathrm{~mm}$.

On day 3, IOP was RE, 7 and LE, $10 \mathrm{~mm} \mathrm{Hg}$ and the cornea of the right eye was clear. Bilateral argon LPI was performed at temporal-upper iris. LPI setting was $200 \mathrm{~mW}$ energy power, $200 \mu \mathrm{m}$ size, and first 5 shots of $0.2 \mathrm{~s}$, followed by $900 \mathrm{~mW}, 50 \mu \mathrm{m}, 0.02 \mathrm{~s}, 110$ shots on the right eye, and 75 shots on the left. Topical $2 \%$ pilocarpine (15 min interval, 4 times) before and topical apraclonidine $1 \%$ at $60 \mathrm{~min}$ before and immediately after LPI were applied. UBM examinations were repeated before and $2 \mathrm{~h}$ after LPI. Two hours after LPI, uveal effusion was observed at the inferior portion of the right eye (Fig. 2). The left eye was unremarkable. Five hours after argon laser iridotomy, fibrin was observed in the right anterior chamber and IOP in the right eye was $7 \mathrm{~mm} \mathrm{Hg}$. Topical $0.1 \%$ fluorometholone was applied for both eyes and betamethasone ointment was applied on the right eye. On day 4, 1 day after LPI, fibrin in the right anterior chamber had disappeared. UBM examination was repeated and showed that the uveal effusion had disappeared, but engorged episcleral veins were still observed (Fig. 2). Topical $0.1 \%$ fluorometholone was continued for both eyes, but betamethasone ointment was stopped, IOP in the right eye was $8 \mathrm{~mm} \mathrm{Hg}$ and the patient was discharged on day 4.

On day 5 , the patient visited our outpatient clinic for right ocular pain. Her corrected visual acuity was RE 20/20 (S: OD) and LE 20/20 (S: OD). The cup-to-disc ratios were RE, 0.3 and LE, 0.3. Slit-lamp examination showed clear cornea and cells (+++) in the right anterior chamber. Gonioscopy revealed narrow but open angle bilaterally. IOP was RE, 10 and LE, 12 $\mathrm{mm}$ Hg. Topical $0.1 \%$ fluorometholone was continued. UBM examination was repeated on day 6 and showed recurrence of small uveal effusion at the superior and inferior portion in her right eye and engorgement of episcleral vein also remained (Fig. 2). Betamethasone ointment was applied twice daily on the right eye. On day 7, ocular pain had disappeared. On 


\section{Case Reports in Ophthalmology}

\begin{tabular}{l|l}
\hline DOI: 10.1159/000455038 & $\begin{array}{l}\text { ○ } 2017 \text { The Author(s). Published by S. Karger AG, Basel } \\
\text { www.karger.com/cop }\end{array}$ \\
\hline
\end{tabular}

Sakai et al.: Recurrent Uveal Effusion after Laser Iridotomy

day 11, IOP was RE, 12 and LE, $12 \mathrm{~mm} \mathrm{Hg}$. UBM examination showed total disappearance of uveal effusion and engorged episcleral vessels (Fig. 2). Then all medical treatment was discontinued.

\section{Discussion}

Studies using UBM showed frequent occurrence of uveal effusion following ocular surgeries such as filtering procedure [8], scleral buckling [9], pan-retinal photocoagulation [10, 11], and laser iridotomy [4]. Also ocular inflammation such as Vogt-Koyanagi-Harada disease [12] and increased episcleral venous pressure such as Sturge-Weber syndrome [13] are known to be associated with uveal effusion.

Uveal effusion is believed to be an abnormal accumulation of fluid into the suprachoroidal space, a potential space between the choroid and sclera, resulting from exudation from choroidal capillary wall secondary to hypotony or abnormal vascular permeability, otherwise a direct inflow of aqueous humor from the anterior chamber with or without a cyclodialysis [14]. Each of ocular hypotony, inflammation, or increased episcleral venous pressure and their combination may result in uveal effusion development. But the exact mechanism for the development of uveal effusion is still unclear.

Ocular hypotony is known to occur in the postcongestive phase of APAC in some cases, and reduced aqueous secretion was considered as the mechanism for hypotony [15]. In our case, ocular hypotony (RE, $7 \mathrm{~mm}$ Hg on day 3) after PACD attack was observed and might play a role on the formation of small uveal effusion. However, ocular hypotony itself might not have a crucial effect on the development of the effusion, because the effusion disappeared on day 4 and developed again on day 5 without hypotony (RE, $10 \mathrm{~mm} \mathrm{Hg}$ ) or sudden IOP reduction.

Prominent episcleral vessels were observed by UBM during the treatment of the acute attack and they remained after medical and laser treatment. Conjunctival congestion is a major sign in APAC patients, because elevated intraocular pressure, more than blood pressure of ciliary arteries, results in the congestion of veins connected to each other and making a continuous network at the limbus such as episcleral veins, intrascleral plexus, deep scleral plexus, episcleral efferent veins, and ciliary veins. Increasing ciliary venous pressure was considered to be one of the major factors for uveal effusion [14, 15]. In this case, prominent episcleral veins and ciliary vein might be a cofactor of development of the uveal effusion.

Uveal effusion was reported to be associated with ocular inflammation such as uveitis. In this case, inflammation may play a most important role for the formation of uveal effusion, because the uveal effusion appeared shortly after laser irradiation and it disappeared with the use of steroid eye ointment and was recurrent after stopping the therapy. Also ocular pain associated with prostaglandins after laser irradiation may be associated with the formation of uveal effusion. Each of APAC itself and LPI procedure is known to induce iritis, so that uveal effusion may easily occur after LPI in an APAC patient. Bilateral acetazolamideinduced choroidal effusion following cataract surgery has been reported previously [16]. Oral acetazolamide given to our patient may be associated with the development of uveal effusion, but the recurrence of the effusion could not be accounted for by the use of acetazolamide. We believe that a synergistic effect of ocular hypotony, increasing episcleral venous pressure, and ocular inflammation might have resulted in the recurrent uveal effusion in this case. 
In summary, we showed a case of recurrent uveal effusion after argon LPI in a patient with APAC. Subclinical uveal effusion diagnosed by UBM occurred immediately after LPI. Ocular inflammation induced by laser irradiation, increased episcleral venous pressure after APAC, and/or ocular hypotony might be the factors causing uveal effusion following LPI. UBM is a useful modality to observe changes in suprachoroidal space and congested ciliary veins following laser therapy or APAC.

\section{Statement of Ethics}

This report followed the tenets of the Declaration of Helsinki. The patient gave written informed consent for her participation.

\section{Disclosure Statement}

The authors have no proprietary interest.

\section{References}

1 Ritch R, Liebmann JM: Laser iridotomy and peripheral iridoplasty; in Ritch R, Shields MB, Kurpin T (eds). The Glaucomas, 2nd ed. St. Louis, Mosby, 1996, pp 1549-1573.

2 Teoh LOC, Ishikawa H, Liebmann JM, Ritch R: Late closure of argon laser iridotomies following regrowth of iris pigment epithelium. Arch Ophthalmol 2000;118:989-990.

-3 Corriveau LA, Nasr Y, Fanous S: Choroidal and retinal detachment following argon laser iridotomy. Can J Ophthalmol 1986;21:107-108.

4 Sakai H, Ishikawa H, Shinzato M, et al: Prevalence of ciliochoroidal effusion after prophylactic laser iridotomy. Am J Ophthalmol 2003;136:537-538.

-5 Sakai H, Morine-Shinjyo S, Shinzato M: Uveal effusion in primary angle-closure glaucoma. Ophthalmology 2005;112:413-419.

-6 Kumar RS, Quek D, Lee KY, et al: Confirmation of the presence of uveal effusion in Asian eyes with primary angle closure glaucoma: an ultrasound biomicroscopy study. Arch Ophthalmol 2008;126:1647-1651.

-7 You YA, Zhu LR, Wen JQ, et al: Ultrasound biomicroscopic evaluation of uveal effusion in acute primary angle closure. J Glaucoma 2015;24:656-661.

8 Martinez-Bello C, Capeans C, Sanchez-Salorio M: Ultrasound biomicroscopy in the diagnosis of supraciliochoroidal fluid after trabeculectomy. Am J Ophthalmol 1999;128:372-375.

9 Maruyama Y, Yuki T, Nanbu S, et al: Ciliary detachment following retinal detachment surgery. Rinsyo Ganka 1996;50:1543-1548.

10 Yuki T, Kimura Y, Nanbu S, Maruyama Y: Ciliochoroidal detachment following photocoagulation to one quadrant of the fundus with diabetic retinopathy. Rinsyo Ganka 1996;50:1527-1534.

11 Gentile RC, Stegman Z, Liebmann JM, Dayan AR, Tello C, Walsh JB, Ritch R: Risk factors for ciliochoroidal effusion after panretinal photocoagulation. Ophthalmology 1996;103:827-832.

-12 Gohdo T, Tsukahara S: Ultrasound biomicroscopy of shallow anterior chamber in Vogt-KoyanagiHarada syndrome. Am J Ophthalmol 1996;122:112-114.

$\$ 13$ Sakai H, Sakima N, Nakamura Y, Nakamura Y, Hayakawa K, Sawaguchi S: Ciliochoroidal effusion induced by topical latanoprost in a patient with Sturge-Weber syndrome. Jpn J Ophthalmol 2002;46:553-555.

$\checkmark 14$ Bellows AR, Chylack LT Jr, Hutchinson BT: Choroidal detachment: clinical manifestation, therapy and mechanism of formation. Ophthalmology 1981;88:1107-1115.

15 Brubaker RF, Pederson JE: Ciliochoroidal detachment. Surv Ophthalmol 1983;27:281-289.

16 Parthasarathi S, Myint K, Singh G, Mon S, Sadasivam P, Dhillon B: Bilateral acetazolamide-induced choroidal effusion following cataract surgery. Eye 2007;21:870-872. 


\section{Case Reports in Ophthalmology}

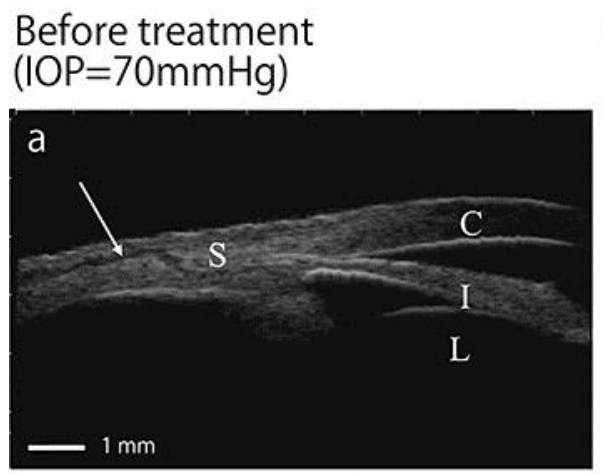

\section{One day after treatment $(\mathrm{IOP}=9 \mathrm{mmHg})$}
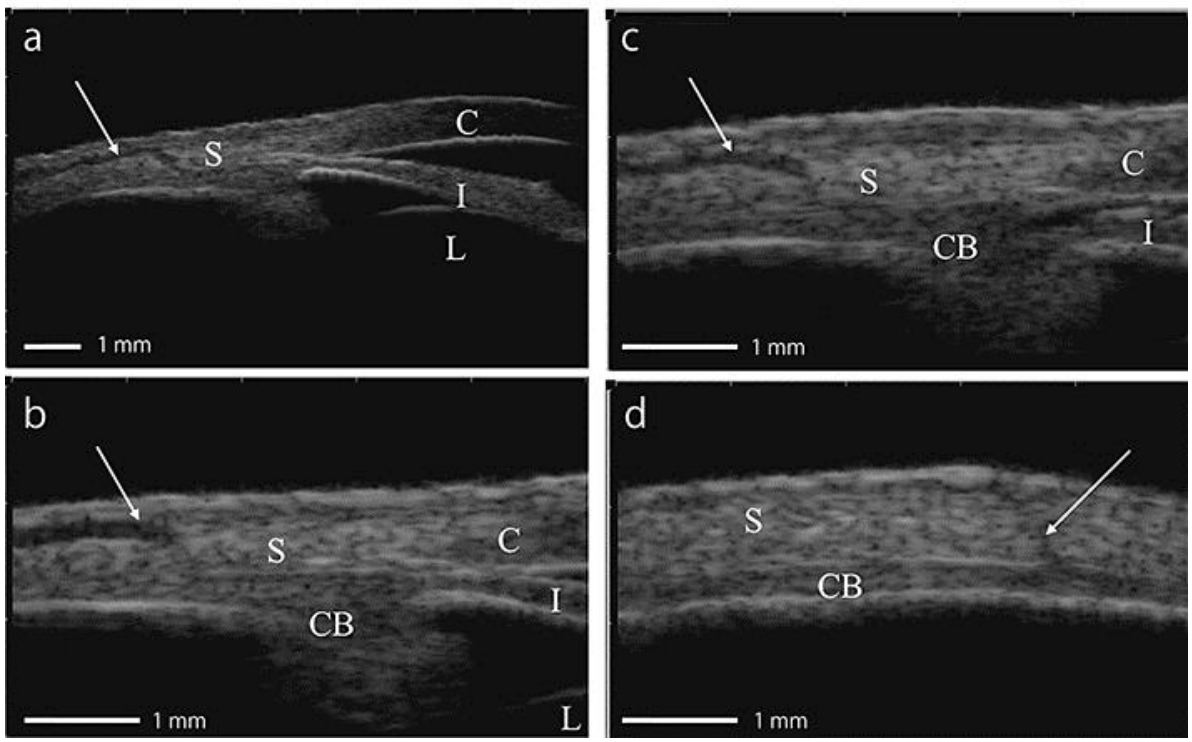

Fig. 1. UBM findings of the right eye at the superior portion with engorged episcleral efferent vein (arrow) on the first day (IOP = $70 \mathrm{~mm} \mathrm{Hg}$; a, b) and 1 day after treatment (IOP = $9 \mathrm{~mm} \mathrm{Hg}$; c d). Scale bar, $500 \mu \mathrm{m}$. $\mathrm{S}$, sclera; C, cornea; CB, ciliary body; I, iris; L, lens.
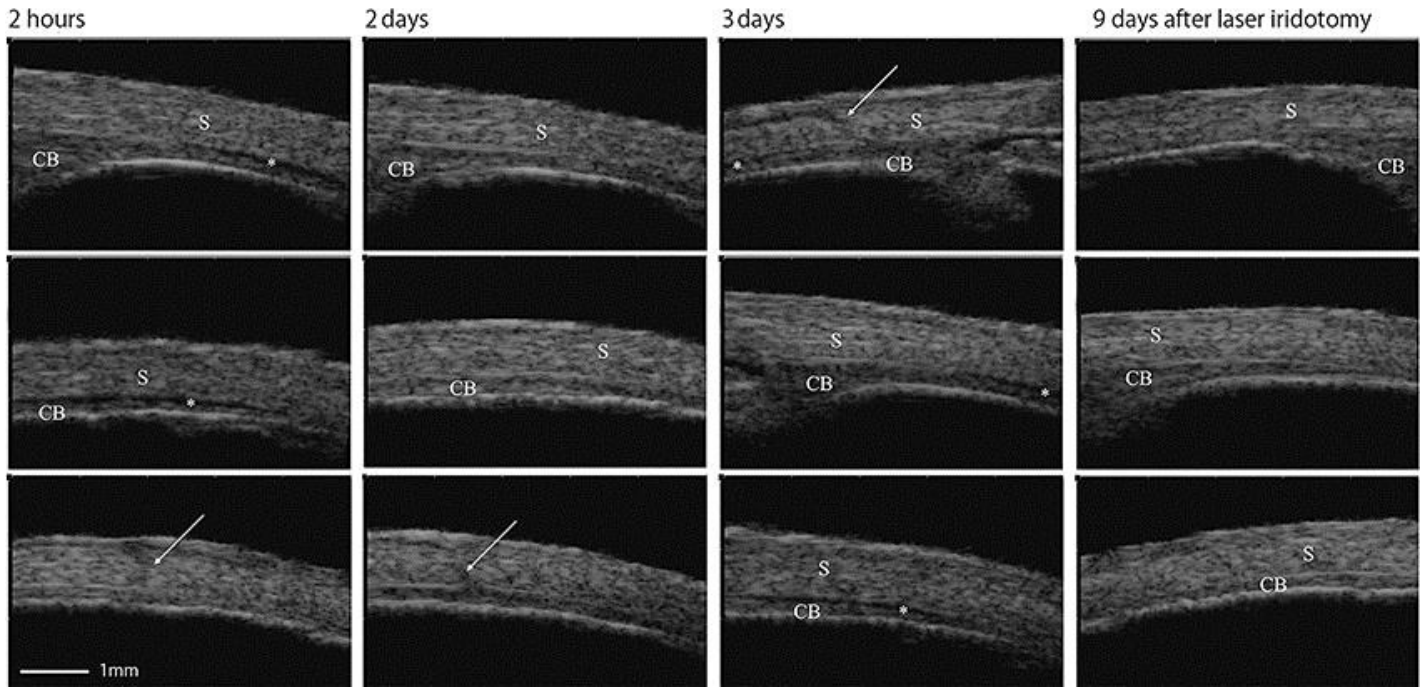

Fig. 2. UBM findings of the right eye $2 \mathrm{~h}$ as well as 2, 3, and 9 days after laser peripheral iridotomy. Small uveal effusion $\left(^{*}\right)$ was observed as a hypoechographic line between the scleral and ciliary body $2 \mathrm{~h}$ and 3 days after laser treatment. An engorged episcleral efferent vein (arrow) was evident $2 \mathrm{~h}$ as well as 2 and 3 days after treatment. Scale bar, $500 \mu \mathrm{m}$. S, sclera; CB, ciliary body. 